\title{
Erratum to: The Spanish Republican Exile: Identity, Belonging and Memory in the Digital World
}

\author{
Lidia Bocanegra Barbecho and Maurizio Toscano
}

\section{Erratum to:}

K.J. Borowiecki et al. (eds.), Cultural Heritage in a Changing World DOI 10.1007/978-3-319-29544-2_14, (C) The Author(s) 2016

The affiliation of the author Maurizio Toscano has been incorrectly captured in Page 237 and the correct affiliation is as follows:

M. Toscano Eachtra Archaeological Projects Ltd., Lickybeg, Clashmore, Co. Waterford, Ireland e-mail:maurizio@eachtra.ie 